\title{
LIVROS ILUSTRADOS TÁTEIS: ACESSO À LITERATURA PARA CRIANÇAS COM DEFICIÊNCIA VISUAL EM FASE DE LETRAMENTO
}

\author{
Cláudia Rodrigues de Freitas \\ Universidade Federal do Rio Grande do Sul - UFRGS (Brasil) \\ freitascrd@gmail.com https://orcid.org/0000-0002-7105-8539 \\ Mauren Lucia Tezzari \\ Escola Municipal de Ensino Fundamental Jean Piaget \\ Rede Municipal de Ensino de Porto Alegre - RS (Brasil) \\ maurentezzari@gmail.com https://orcid.org/0000-0001-6060-9107 \\ Roberta Stockmanns \\ Instituto Federal Catarinense, IF-Catarinense (Brasil) \\ robertastockmanns@gmail.com https://orcid.org/0000-0003-4996-9632 \\ Eduardo Cardoso \\ Universidade Federal do Rio Grande do Sul - UFRGS (Brasil) \\ eduardo.cardoso@ufrgs.br https://orcid.org/0000-0002-1202-1779
}

\begin{abstract}
Resumo. Este trabalho tem origem em pesquisa desenvolvida pelo MULTI no âmbito do Núcleo de Estudos em Políticas de Inclusão Escolar (NEPIE/UFRGS). O referido grupo dedica-se, principalmente, ao desenvolvimento e à produção de livros ilustrados táteis para crianças e, de modo especial, àquelas com deficiência visual em fase de letramento, sendo esse o principal objetivo da investigação. O presente texto tem origem a partir da conclusão da primeira fase de uma pesquisa em andamento, cujo objetivo principal é o de desenvolver livros ilustrados táteis para crianças com deficiência visual em processo de letramento. A temática fundamental insere-se na proposta de ampliação e de qualificação da inclusão através da acessibilidade a livros infantis para todas as crianças. O referencial teórico sustenta-se em estudiosos como Polato (2010, 2013), Piccardi (2011) e Nuernberg (2010), entre outros. A pesquisa conta com financiamento de projeto da CAPES Chamada Universal-2016. O grupo MULTI é composto por profissionais: professores de educação especial, consultores em deficiência visual, especialistas em design e estudantes de graduação de diferentes áreas. A pesquisa, hoje, conta com algumas dezenas de protótipos desenvolvidos junto ao grupo de pesquisa. Como resultado inicial, apresenta a publicação de uma história em versão impressa em braille e tinta em fonte ampliada, com imagens táteis ilustradas, com versão digital em audiolivro com audiodescrição. Dois outros livros estão em fase final de produção. A alegria das crianças que tiveram acesso aos livros define a direção e o andamento da pesquisa. Ainda se enfrentam alguns desafios, entre os quais, o custo para a produção dos livros.
\end{abstract}

Palavras-chave: livro ilustrado tátil, letramento, acessibilidade, deficiência visual, inclusão.

\section{TACTILE ILLUSTRATED BOOKS: ACCESS TO LITERATURE FOR CHILDREN WITH VISUAL IMPAIRMENT IN LITERACY PHASE}

\begin{abstract}
This paper comes from a research developed by the MULTI group in the Study Group on School Inclusion Policies (NEPIE/UFRGS). This group is also dedicated to the development and production of tactile illustrated books for children especially for those with visual impairment, in the literacy phase, which is the main objective of this research. This article is based on the conclusion of the first phase of a research, whose main objective is to develop tactile illustrated books for children with visual impairment. The fundamental topic is part of the proposal to expand and qualify inclusion through accessible books for all
\end{abstract}


children. Polato (2010, 2013), Piccardi (2011) and Nuernberg (2010) support the theoretical contribution, among others. The research is financing by CAPES Universal Call -2016. Professionals like special education teachers, visually impaired consultants, design specialists and undergraduate students from different fields compose the group MULTI. The research group has developed a few dozen prototypes until now. As an initial result of the research, there is the publication of a tactile illustrated book printed in Braille and large font too with digital audiobook and audio description. Two other books are in the final stages of production. The happiness of the children who had access to the books defines the direction and progress of the research. Some challenges came across as the cost of producing the books.

Keywords: tactile illustrated book, literacy, accessibility, visual impairment, inclusion.

\title{
LIBROS ILUSTRADOS TÁCTILES: ACCESO A LA LITERATURA PARA NIÑOS CON DISCAPACIDAD VISUAL EN FASE DE ALFABETIZACIÓN
}

\begin{abstract}
Resumen. Este trabajo se origina de una investigación desarrollada por el grupo MULTI, en el ámbito de Grupo de estudio sobre políticas de inclusión escolar (NEPIE/UFRGS). El referido grupo se dedica principalmente al desarrollo y a la producción de libros ilustrados táctiles para niños y, de manera especial, a aquellos con discapacidad visual, en fase de alfabetización, siendo este el principal objetivo de la investigación. El presente texto se originó a partir de la conclusión de la primera fase de un estudio en curso, cuya principal función es el desarrollo de libros ilustrados táctiles para niños con discapacidad visual en proceso de alfabetización. La temática fundamental se insiere en la propuesta de amplificación y calificación de la inclusión a través del acceso a libros infantiles para todos los niños. El referencial teórico se sostiene en estudiosos como Polato (2010.2013), Piccardi (2011) y Nuernberg (2010), entre otros. La investigación cuenta con la financiación del proyecto de la CAPES llamada universal -2016. El grupo MULTI es compuesto por profesionales: profesores de educación especial, consultores en discapacidad visual, especialistas en design y estudiantes de graduación de diferentes áreas. La investigación posee algunas decenas de prototipos desarrollados junto al grupo de pesquisa. Como resultado inicial del estudio hay una publicación de una historia impresa en braille y tinta en fuente ampliada, con imágenes táctiles ilustradas, con versión digital en audiolibro con audiodescripción. Otros dos libros están en fase final de producción. La alegría de los niños que tuvieron acceso a los libros define la dirección y el curso de la pesquisa. Todavía se enfrentan algunos desafíos, entre ellos, el costo de la producción de los libros.
\end{abstract}

Palabras clave: libro ilustrado táctil, -letramiento, accesibilidad, discapacidad visual, inclusión.

\section{Introdução}

Toda a pessoa tem o direito de participar livremente da vida cultural da comunidade, de fruir as artes e de participar do processo científico e seus benefícios

(ONU, 1948)

A busca por uma sociedade mais justa e igualitária, por meio da qualificação e da ampliação da inclusão, concretiza-se, também, quando todas as crianças podem ter acessibilidade aos livros infantis. No Brasil, os processos de inclusão escolar vêm tomando forma nas práticas pedagógicas, nos marcos legais e se fazem presentes nos debates e nas reflexões que acontecem no cotidiano das escolas, buscando sustentação na formação continuada e nos dispositivos desenvolvidos para tal fim.

O movimento pela inclusão existe há mais de 20 anos no Brasil e diversos grupos de pesquisa se ocupam intensamente em investigar e em propor formação aos professores 
(Jesus, Baptista e Caiado, 2013) uma vez que isso se pode considerar um ponto nevrálgico do processo. Abordam-se distintas áreas da educação: práticas pedagógicas inclusivas direcionadas às diferentes áreas do conhecimento, informática, dispositivos e estratégias facilitadores da inclusão, tecnologia assistiva e outros, sendo contempladas com trabalhos voltados à adequação de diferentes materiais em uma perspectiva inclusiva. No entanto, encontram-se poucos relatos de pesquisas desencadeadas na direção de pensar livros ilustrados táteis para crianças com deficiência visual.

O presente texto tem origem a partir da conclusão da primeira fase de uma pesquisa em andamento, cujo objetivo principal é o de desenvolver livros ilustrados táteis para crianças com deficiência visual em processo de letramento. Como já se mencionou anteriormente, o projeto de pesquisa desenvolve-se no âmbito do NEPIE na Universidade Federal do Rio Grande do Sul (UFRGS), pelo grupo Multii. A temática central deste projeto insere-se na proposta de ampliação e de qualificação da inclusão por meio da acessibilidade a livros infantis para crianças com deficiência visual. A pesquisa conta com financiamento de projeto da Chamada Universal- $2016 \mathrm{CNPq}$.

O movimento pela inclusão escolar toma a perspectiva ética do respeito e do reconhecimento da diversidade humana como mote e prática. São muitas as datas contando sobre esse movimento na linha do tempo. No Brasil, a partir dos anos 2000, há um incremento significativo nas políticas públicas no sentido de garantir as condições necessárias para efetivar a inclusão na escola. A Lei $n^{\circ} 10.753(2003)$ institui a Política Nacional do Livro, assegurando, ao cidadão, o pleno exercício do direito de acesso e de uso do livro como "meio principal e insubstituível da difusão da cultura e transmissão do conhecimento, do fomento à pesquisa social e científica, da conservação do patrimônio nacional, da transformação e aperfeiçoamento social e da melhoria da qualidade de vida" (Brasil, 2003, p. 1).

$\mathrm{O}$ fomento e o apoio à produção, à edição, à difusão, à distribuição e à comercialização do livro estão expressos em tal normativa, que busca, igualmente, promover e incentivar o hábito da leitura. Para isso, é preciso o livro ter uma forma, uma escrita e texturas capazes de possibilitar uma leitura integral (escrita e imagens) por crianças com baixa visão.

Assim, considerando as atuais políticas públicas no campo da educação, as demandas advindas do desafio de tornar a escola um espaço para todos, bem como as lacunas existentes na produção de livros infantis acessíveis a crianças com deficiência visual, o grupo, como lócus de pesquisa, vem articulando investigações da área com os conhecimentos multidisciplinares de um coletivo formado por profissionais como professores de educação especial, consultores em deficiência visual, especialistas em design e estudantes de graduação de diferentes áreas.

\section{O livro ilustrado tátil}

Ao nos debruçarmos sobre a temática da inclusão escolar no Brasil, deparamonos com diversas problematizações e provocações, principalmente quando discutimos o acesso das crianças à educação infantil e aos primeiros anos do ensino fundamental, bem como o apoio às suas necessidades específicas (quando isso se faz necessário). Conforme aponta o Anuário Brasileiro da Educação Básica:

... hoje, como mostra a Prova ABC 2011, ..., 56,1\% das crianças atingem o grau adequado de proficiência em leitura ao final dos três primeiros anos do Ensino 
Fundamental.É um desafio gigantesco, mas que certamente terá repercussão sobre todas as etapas posteriores. Os resultados das avaliações, também registradas no Anuário Brasileiro de Educação Básica 2013, mostram as imensas dificuldades dos jovens com a leitura e a interpretação de textos - que acarretam o atraso em todas as disciplinas e, mais à frente, influenciam os elevados índices de analfabetismo funcional da população adulta (2014, p. 9)

O programa "Pacto pela Alfabetização na Idade Certa"ii indica que a inclusão (acesso e aprendizagem) nos primeiros anos da Educação Básica depende, dentre vários fatores, da acessibilidade aos materiais culturais como os livros infantis. Constatamos que os livros disponíveis, no Brasil, para crianças pequenas, carecem de elementos que os qualifiquem e permitam o acesso por parte de todas, como: escrita em braille, escrita em tinta ampliada, inserção de libras e pictogramas, dentre outros a fim de permitir a leitura a um grupo maior de sujeitos.

Os livros ilustrados táteis constituem-se em uma alternativa para essa carência verificada, sendo desenvolvidos para crianças com deficiência visual, baixa visão ou cegueira. As obras apresentam características muito específicas: ilustrações criadas com diferentes materiais e texturas, textos escritos tanto em braille quanto em fonte ampliada (Piccardi, 2011). Segundo essa autora, os primeiros livros ilustrados táteis para crianças foram produzidos na Itália pelo Instituto dei Ciechi, em Milão, no início dos anos 70. Sobre tal questão, complementa: "Estes são os livros que surgiram para atender às necessidades educacionais das crianças com deficiência visual, mas, na realidade, como tem sido repetidamente enfatizado, em diferentes contextos, são livros utilizáveis por todas as crianças, respondendo assim ao princípio da acessibilidade" (Piccardi, 2011, p. $1)$.

Pensar o livro ilustrado tátil para crianças com deficiência visual parte de pensar anteriormente no livro enquanto uma publicação para o público infantil e, como tal, sobre os princípios que deve seguir.

Para Lins (2003), o livro infantil deve ser pensado como um todo, envolvendo pesquisa, conhecimento técnico, harmonia entre texto e imagem, sendo resultado de um projeto de design. Devem-se analisar elementos dos livros infantis que necessitam de uma forma integrada de trabalho, sempre considerando a fase de desenvolvimento e as singularidades em relação ao acesso das crianças às quais o livro se destina, ou seja, o formato, o suporte, a estrutura, o layout, o texto e a imagem.

Além disso, a produção de livros em braille e com imagens bidimensionais é um desafio no cenário editorial atual, especialmente o brasileiro, haja vista serem livros que exigem um trabalho meticuloso de produção, acarretando um custo elevado. Além disso, dá-se a dificuldade de serem testados e confeccionados em grande escala. As impressões são poucas, pontuais e, quando se efetivam, acontecem em tiragem quase inexpressiva, reduzindo dramaticamente o acesso ao livro.

Para que o encontro entre os livros e os seus leitores ocorra de forma efetiva, consideramos fundamental a incorporação de estratégias e elementos de Tecnologias Assistivas (TA). De acordo com Passerino (2015) é preciso pensar a TA não somente como um conjunto de recursos que amplia ou proporciona habilidades funcionais, mas também como estratégia metodológica que, juntamente com os recursos, atende às necessidades de autonomia e de qualidade de vida da pessoa com deficiência.

Destacamos que na presente pesquisa, os recursos de TA vêm sendo utilizados e testados com o intuito de empregá-los na produção e na adequação de livros infantis para 
crianças com deficiência visual, intelectual, com autismo e surdez, assim como para crianças em situação de imigração que, desconhecendo a língua do nosso país, podem encontrar-se em situação de desvantagem quando não têm acesso a um livro em formato que lhes seja acessível.

Mediar o acesso é forma de garantir o que diz a Convenção da ONU referendada constitucionalmente pelo país, reconhecendo que a deficiência é um conceito em evolução e que resulta da interação entre as pessoas com deficiência e as barreiras atitudinais e ambientais impeditivas de sua plena e efetiva participação na sociedade em igualdade de oportunidades com as demais pessoas (Brasil, 2009, s. p.).

Remover barreiras de acesso a livros infantis significa investir não apenas no contexto escolar, mas também em outros contextos sociais nos quais a presença do livro seja garantida a todas as crianças. Nuernberg (2010, p. 136) amplia essa discussão referendando a ideia de que garantir às pessoas "maiores condições de usufruírem dos artefatos culturais organizados visualmente, como por exemplo, os livros infantis ilustrados" é fundamental em uma sociedade que se pensa de forma inclusiva.

Hoje, no mercado, encontramos uma variedade muito grande de formatos e de suportes para livros infantis. Existem livros de pano, madeira, metal e plástico; livros com som, cheiro e textura; livros origami e livros pop-up (Lins, 2003). Para se tomar uma decisão a respeito de qual o suporte mais adequado, deve-se ter em mente a quem ele se destina.

No que diz respeito à estrutura e layout do livro infantil, alguns autores o comparam com o cinema e dizem que podemos controlar as imagens do livro como um diretor controla a câmera. É possível explorar profundidade de campo ao mover os personagens entre o primeiro e o segundo plano, alterar o 'ângulo da câmera'. Tais recursos trazem ao livro a noção de ritmo e de movimento, essencial para prender a atenção dos pequenos leitores (Linden, 2011; McCannon, Thornton e Williams, 2008). Outra estratégia para se criar um bom ritmo à história é alternar, no mesmo livro, diferentes tipos de diagramação. Linden (2011) apresenta três tipos de relações entre imagem e texto, que podem ser utilizadas de forma combinada ou como padrão ao longo de toda narrativa: imagens isoladas, que apresentam o texto e a imagem em páginas separadas; as imagens sequenciais, que são uma sequência de imagens articuladas, como nas histórias em quadrinhos; e as imagens associadas, que são imagens que mesclam o texto e a imagem de forma fluida, sendo essa a mais próxima de uma organização adequada ao público com deficiência visual, tendo vista possibilitar a transição entre texto e imagem de maneira ordenada e equilibrada.

Em contrapartida, enquanto a ilustração ocorre de forma mais subjetiva, é preciso atentar-se a certos cuidados ao integrá-la com o texto. Lourenço (2011) traz dois conceitos a serem levados em consideração ao aplicar o texto nos livros infantis: legibilidade, referindo-se à forma das letras e ao seu espaço entrelinhas, entreletras e entrepalavras, e leiturabilidade, que se relaciona com a compreensão do texto.

Para se obter uma boa legibilidade, segundo Lourenço (2011), são mais adequadas tipografias sem serifa, com o espaço entrelinhas grande o suficiente para haver uma diferenciação de uma linha a outra, assim como maior espaço entre letras e entre palavras. Quanto à leiturabilidade, o autor enfatiza a importância de manter poucos caracteres por linha e poucas palavras por página a fim de o leitor iniciante sentir-se capaz de realizar a leitura por conta própria. Tais orientações contribuem, de modo semelhante, para a redação de livros para crianças com deficiência, pois considera a eficiência visual de cada 
leitor e a possibilidade da escrita também em outros formatos, como o braille e a escrita ampliada. No desenvolvimento das atividades de pesquisa, o MULTI busca considerar todos esses aspectos, daí a importância da multiplicidade de áreas presentes no grupo por meio de seus integrantes.

Os livros desenvolvidos pelo grupo de pesquisa têm buscado combinar os principais elementos de acessibilidade, tais como: imagens bidimensionais, braille e fonte ampliada, contando ainda com a inserção de CD elou QR Code com (recursos eletrônicos que possibilitam escutar a história em áudio e desfrutar de audiodescrição).

Para garantir que o livro seja efetivamente acessível e tátil, mostra-se necessário articular conhecimentos multidisciplinares na sua idealização e produção. Em nosso grupo, possibilitou-se, efetivamente, reunir uma equipe composta por professores especialistas em educação especial, consultores em deficiência visual, especialistas em design, mestrandos, doutorandos e estudantes de graduação de diferentes cursos e unidades da UFRGS. Nos encontros semanais de pesquisa, tem-se a oportunidade de discutir aspectos teóricos, assim como desenvolver textos e imagens bidimensionais para os livros. As imagens passam pelos ajustes considerados necessários, juntamente com as considerações significativas apontadas pelas consultoras.

\section{Percurso metodológico}

A proposta metodológica adotada tem buscado garantir a tessitura de uma pesquisa-intervenção. A primeira fase da pesquisa aconteceu ao longo de quatro anos, tendo sido sistematizada, inicialmente, por meio de reuniões de estudo teórico, análise de produções de livros brasileiros e estrangeiros, organização do curso de extensão universitária, sempre tendo como foco a produção de livros ilustrados táteis.

A ênfase na processualidade permitiu a produção de dezenas de protótipos e a publicação de um livro ilustrado tátil.

A produção de dados se deu conciliando estudo, análise, mediação de livros junto a crianças com deficiência visual, finalizando com um livro publicado e mais dois em processo. Os protótipos ofereceram importante recurso à pesquisa.

\section{Principais ações}

A leitura de material selecionado como artigos, dissertações e teses (nacionais e internacionais), bem como a análise de livros disponíveis no mercado nacional e internacional vêm garantindo o andamento da pesquisa ${ }^{\text {iii }}$.

Durante o processo de pesquisa, ofereceram-se três momentos de extensão, os quais permitiram aos professores do Atendimento Educacional Especializado conhecer, desenvolver e oferecer elementos desde suas práticas escolares no desenvolvimento da pesquisa. A seleção das professoras que participaram da pesquisa/extensão considerou como critério a sua atuação em redes municipais elou estadual e em escola. As professoras selecionadas deveriam ter alunos com baixa visão regularmente matriculados em suas escolas; disponibilidade de inserir em seu fazer a apresentação dos livros às crianças. A ação possibilitou leituras e discussões teóricas, a definição de histórias, personagens, e a escolha criteriosa de materiais a serem inseridos. Essa etapa realizou-se de modo a possibilitar um acompanhamento da produção visando à avaliação do protótipo do livro em processo. Contatamos nossa equipe de consultoras para isso. Pontos como a escolha 
de materiais, a organização no espaço do suporte, a acessibilidade e a adequação do livro para cada criança foram aspectos intensamente discutidos.

\section{Apostando na produção de livros ilustrados táteis}

O enfoque deste projeto de pesquisa aconteceu por meio da realização de atividades de investigação, desenvolvimento e inovação na produção de livros ilustrados táteis realizada na FACED-UFRGS. Para a produção dos protótipos, organizou-se um suporte para os livros (livro base), conforme a figura 01. O suporte ${ }^{\text {iv }}$ produziu-se pela Gráfica da Universidade por meio de fomento da PROREXT - Pró-Reitoria de Extensão da UFRGS.

O suporte permitiu a produção de protótipos muito resistentes. Tal fator é importante, considerando-se serem destinados a crianças pequenas. $\mathrm{O}$ suporte permite a abertura total do livro, permitindo às páginas apresentarem-se planas, viabilizando a inserção dos elementos necessários à produção do livro e à posterior leitura pelas crianças. Possibilitou-se constatar, pelo relato das crianças, que o manuseio dos livros foi fácil e convidativo. Esse dispositivo permite a fixação de ilustrações táteis em relevo (tecido, feltro, EVA, miniaturas, etc.), possibilitando a inserção dos elementos necessários para compor a sua produção. Os livros protótipos contam, ainda, com a inserção de escrita em tinta (entre 20pt a 28pt) e braille; sendo este produzido pelo Incluir ${ }^{v}$, também na UFRGS. Os protótipos contaram, igualmente, com dispositivos digitais como o QR Code e CD haja vista poderem oferecer mais autonomia no acesso ao texto dos livros após as primeiras cenas de mediação. Os suportes para os livros contam com uma marca no canto superior direito. $\mathrm{O}$ "e" marca a ideia de eletrônico, diferenciando-o dos demais livros acessíveis táteis organizados pelo grupo e que não contam com tal dispositivo. Essa identificação tátil remete à marcação para materiais de acesso a dispositivos em braille.

O suporte para os livros conta com 8 a 10 páginas, com capa e folhas duplas, permitindo a inserção interna de dispositivos de imagens táteis. A lombada tem cinco centímetros, possibilitando altura entre as páginas para a inserção de elementos táteis necessários à formação da imagem. O tamanho do suporte conta com capa de $30 \times 20 \mathrm{~cm}$ e páginas com um recuo de meio centímetro. As pontas são levemente arredondadas, garantindo anatomia adequada ao manuseio por crianças pequenas.
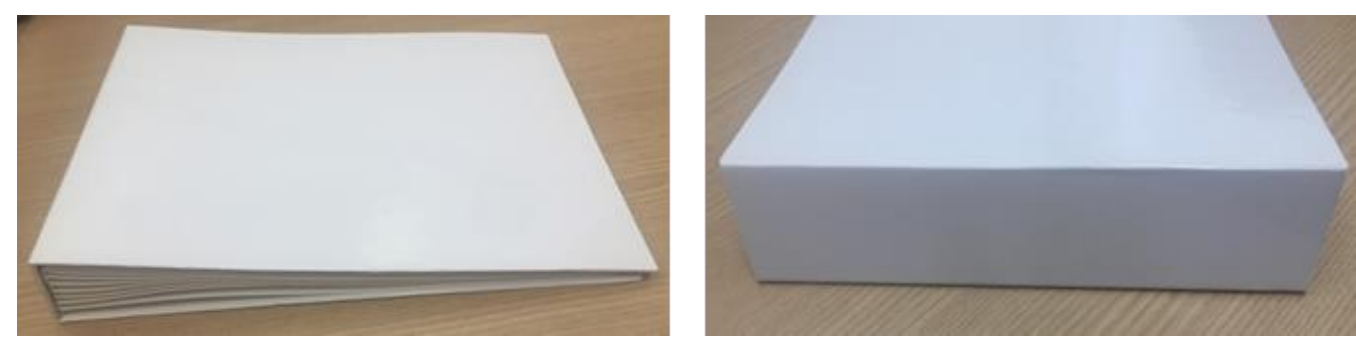

Figura 1. Suporte para os livros (livro base).

Fonte: autores.

Breve descrição da imagem: duas fotografias coloridas e horizontais, lado a lado. Ambas mostram o suporte para o livro, também chamado de livro base, em diferentes posições. O livro base é branco e está sobre um tampo de madeira clara. À esquerda, o livro visto com a capa para cima e a lombada para a esquerda. Tem capa dura e vê-se o miolo do livro com a encadernação de páginas coladas. Â direita, um detalhe da lombada ao se ver de perto: do tipo quadrada e com os cantos levemente arredondados. 


\section{Análise: a mediação do livro ilustrado tátil}

Para o presente artigo, optamos abordar sobre um livro organizado para o projeto de extensão de 2018: o livro protótipo organizado pela professora-pesquisadora, que foi levado a uma criança com deficiência visual em uma escola pública. Durante a realização do Curso de Extensão, trouxemos algumas "pistas" sobre livros ilustrados táteis. Importante lembrar que as professoras integrantes do grupo ofereceram muito de seu saber para constituir importante análise dos livros desenvolvidos. Não só a construção dos livros, mas a tessitura dos encontros também permitiu palpitar, indicar, pesquisar em companhia. O trabalho concretizou-se com a colaboração da "professora artesã", da especialista em braille, da costureira, bordadeira e, por fim, de professoras do Atendimento Educacional Especializado, que muito conhecem sobre seus alunos e suas alunas. Ofereceram-se os livros a crianças na faixa etária de 3 a 8 anos, com baixa visão ou com cegueira. Algumas professoras filmaram a mediação dos livros. Isso em muito contribuiu e enriqueceu nossa análise. Faz-se importante aqui pensar na forma de apresentar o livro, planejando essa mediação. Quanto à importância da mediação para a interação entre a criança e o livro tátil, vale lembrar o papel do mediador.

Inicialmente, a leitura não pode ser independente, a criança deve ser orientada e acompanhada por adultos (pais, professores), com uma leitura do texto em voz alta, que guie a análise das imagens táteis e ajude a fazer uma comparação entre operações mentais, para descobrir semelhanças e diferenças com o objeto real (Piccardi, 2011, p. 5).

Elaborou-se um material denominado "estudo da leitura do livro ilustrado tátil" com o objetivo de auxiliar as professoras na apresentação dos livros às crianças. Esse instrumento serviu de guia e também como ferramenta para relatarem como havia se dado a interação da criança com livro, além de outras importantes considerações. $O$ instrumento solicita informações como: identificação da professora e colaboradora, nome do livro organizado, autoras do livro, idade da criança à qual se ofereceu o livro, escola em que estuda, se tem baixa visão ou cegueira e onde se desencadeou a mediação.

As questões solicitadas no "roteiro" do instrumento eram bem detalhadas com vistas ao relato das professoras de como foi o momento. Entre elas, constam: a criança (re)conhece o braille? Pergunta-se sobre ele? A criança com baixa visão ou cegueira conhecia o braille? Interagiu com ele? Pediu ajuda para entendê-lo? A criança demonstrou gostar da história?

Em um segundo momento, aconteceu a mediação com o livro junto ao grupo no qual a criança está inserida (turma de sala de aula). Após o primeiro contato da criança com o livro, ela e sua professora convidaram os demais colegas para, também, lerem-no. As filmagens produzidas evidenciam que foi um momento muito rico para todos.

\section{Um livro ilustrado tátil: 0 Gato Tonico}

A produção dos livros-protótipos táteis deu-se durante o curso de extensão, podendo ser considerados artesanais, com tiragens pequenas (de 1 a 4 exemplares de cada um).

Segundo Piccardi:

Oferecer à criança a possibilidade de exploração tátil dos objetos que ela conhece em sua tridimensionalidade e que, atacando-os, perderam a primeira característica que é a espacialidade, é o primeiro passo fundamental em direção à representação mental e à simbolização. Posteriormente, podem ser propostos livros ilustrados táteis, de alta similaridade, que propõem objetos não concretos, ou não apenas 
objetos concretos, mas imagens táteis semelhantes ao real, capazes de evocar uma realidade, um objeto ou uma situação que a criança já conhece (Piccardi, 2011, p. $3)$.

Tomamos, como campo de estudo e de análise para este artigo, o livro "O Gato Tonico", confeccionado por três educadoras, tendo a tiragem de seis exemplares. Um deles foi presenteado a uma criança com deficiência visual durante a experiência de leitura, detendo-nos na análise da intervenção realizada com ela.

O livro "Gato Tonico" conta a história de um gato muito curioso que costuma "zanzar" por diversos lugares, nos quais se depara com perigos e surpresas. O livro enfatiza advérbios como: perto, longe, em cima, embaixo, entre outros, os quais estão destacados em negrito na escrita em tinta, conforme podemos observar na figura 02 .

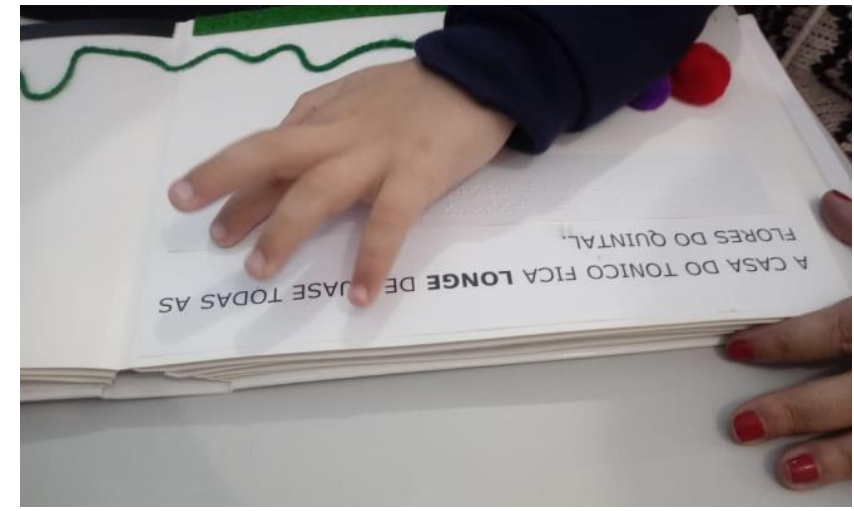

Figura 2. Leitura do livro "Gato Tonico".

Fonte: autores.

Breve descrição da imagem: fotografia horizontal colorida. Sobre uma mesa de tampo cinza, o livro aberto. Tem a página branca com texto em preto na página da direita e algumas figuras em verde e em vermelho parcialmente cobertas pela pequena mão de uma criança que tateia o livro. No canto inferior direito, a mão da mediadora sobre o canto do livro.

A criança, à qual o livro foi apresentado, é um menino de oito anos, que apresenta cegueira congênita e frequenta uma escola pública da rede do Estado do Rio Grande do Sul. A professora-colaboradora escolhida para ter seu relato apresentado promoveu esse momento de interação entre a criança e o livro (confeccionado no curso de extensão) na escola em esta estuda.

O aluno, muito receptivo em participar do momento de leitura do livro, utilizouse de todos os recursos presentes na obra: leitura braille, imagens táteis e escuta da narrativa através do QR Code. O menino, que já tem conhecimento da escrita braille, mostrou-se muito interessado pelo livro ilustrado tátil, tendo, inclusive, questionado o significado de palavras utilizadas na escrita, como zanzar. Demonstrou interesses específicos pelo livro, uma vez que, após a primeira leitura, mediada pela professora, realizou outras duas leituras do livro por iniciativa própria. A figura 03 mostra o momento em que ele explora uma das imagens do livro: o Cachorro General. 


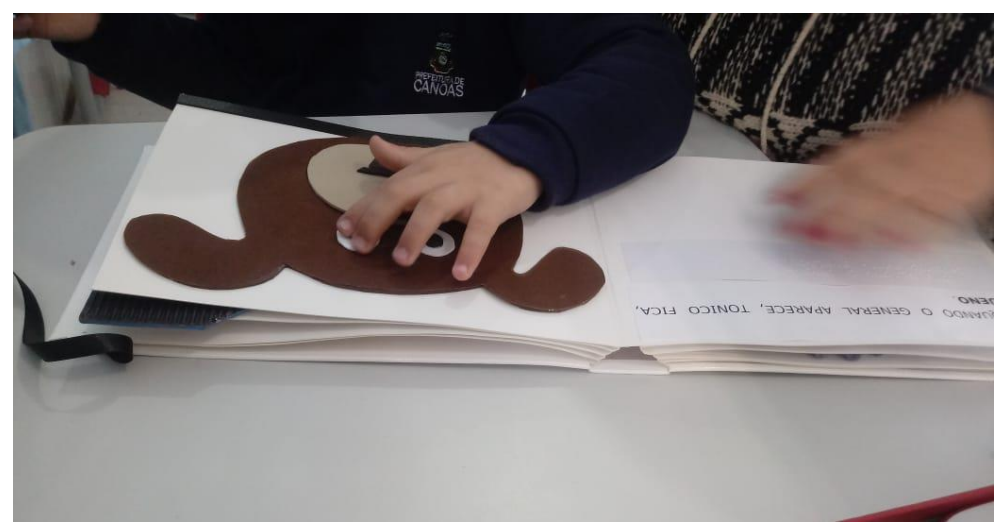

Figura 3. Exploração tátil do livro - imagem do Cachorro General.

Fonte: autores.

Breve descrição da imagem: fotografia horizontal colorida. Sobre uma mesa de tampo cinza, o livro aberto. Tem a página branca com texto em preto na página da direita e a ilustração tátil do Cachorro General na outra. Sobre a imagem, a mão da criança, que explora o personagem. À esquerda, a mediadora.

Na sequência, a figura 04 mostra a interação com outra ilustração tátil: o tapete que o gato Tonico utiliza para se esconder; e a figura 05 mostra a imagem da casa do "gato Tonico".

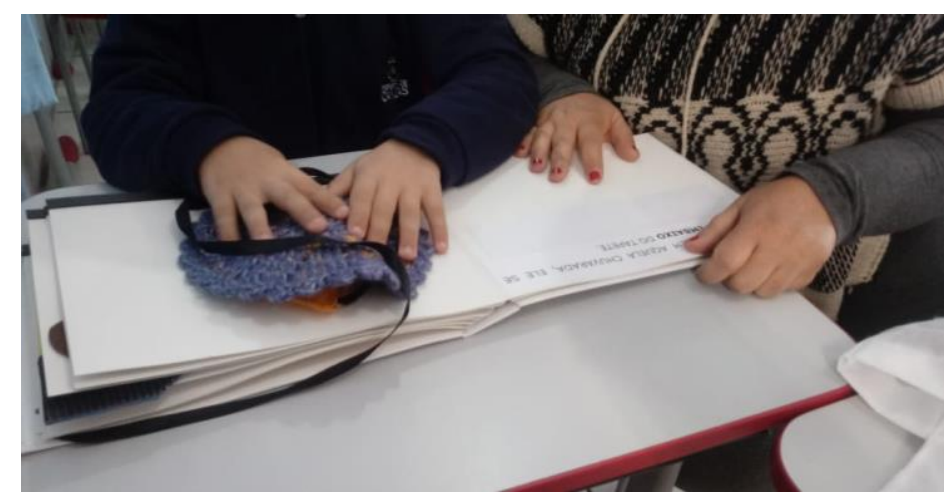

Figura 4. Exploração tátil do livro - imagem tapete do Gato Tonico.

Fonte: autores.

Breve descrição da imagem: fotografia horizontal colorida. Sobre uma mesa de tampo cinza, o livro aberto. Tem a página branca com texto em preto na página da direita e a ilustração tátil do tapete do Gato Tonico na outra. O tapete é feito em lã e amarrado ao livro. Sobre a imagem as mãos da criança, que explora a ilustração tátil. À esquerda, a mediadora segura o livro. 


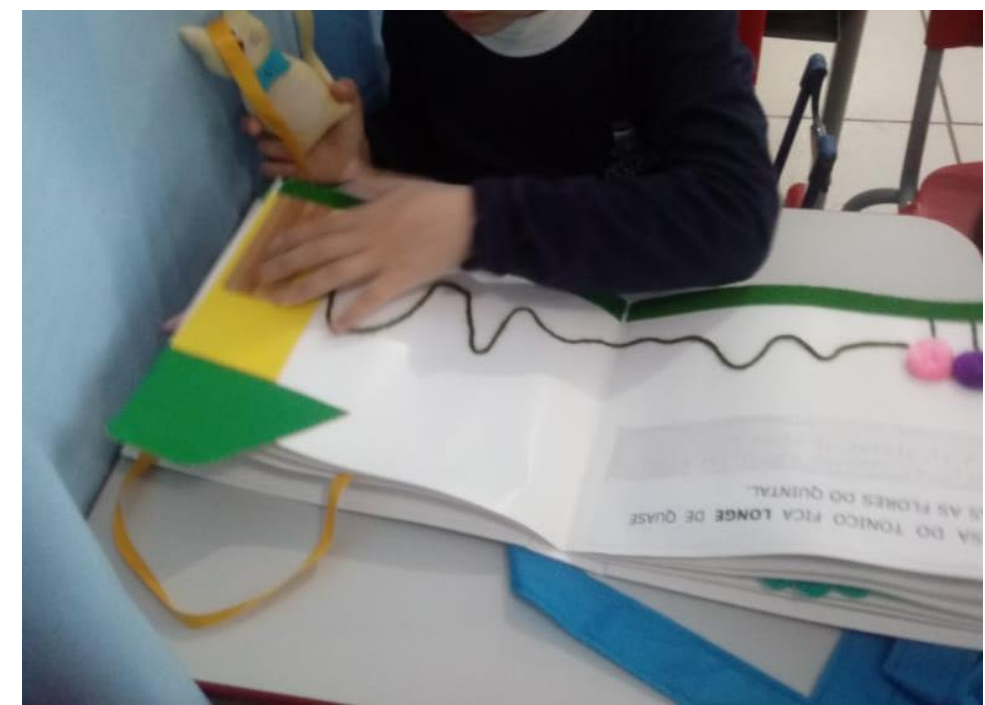

Figura 5. Exploração tátil do livro - imagem da casa do Gato Tonico

Fonte: autores.

Breve Descrição da Imagem: fotografia horizontal colorida. Sobre uma mesa de tampo cinza, o livro aberto. Tem a página branca com texto em preto na página da direita e a ilustração tátil da casa do Gato Tonico na outra. A casa é amarela com telhado verde e está sobre uma linha de base também verde. Sobre a imagem, a mão da criança, que está com o braço apoiado sobre o livro.

Também, possibilitou-se reconhecer que o aluno, após ser convidado a apresentar o livro ao grupo de colegas, demonstra grande interesse em intermediar esse momento. $\mathrm{O}$ menino, que assume o lugar de mediador de leitura, apresenta o livro de forma clara e instiga os colegas a descobrirem os seus elementos, explorando as imagens, a escrita e interpretando a história.

Destacamos a importância de considerar a poderosa possibilidade que livros ilustrados podem oferecer à criança em processo de letramento.

As crianças cegas e com deficiência visual em geral precisam ter livros em suas mãos para aprender que eles são compostos de páginas para girar, que há um alto e um baixo, uma capa e um verso, que devem ser manuseados com cuidado, que não devemos ser retidos e que eles devem ser fechados e guardados após o uso. (Polato, 2013, p. 105).

Quanto à representação das imagens na bidimensionalidade, constatamos que o menino identificou os personagens rapidamente e se ateve a detalhes como: o rabo do gato, as formigas do jardim, o prato vazio de comida do Gato Tonico. A partir do fácil reconhecimento das imagens bidimensionais pela criança com deficiência visual, podese observar que o livro produzido se mostra efetivamente compreensível e de interesse por todos, crianças com e sem deficiência, respondendo, assim, ao princípio da acessibilidade proposto por Passerino e Montardo (2007, p. 14): "ser acessível é permitir o uso", além da promoção da interação e da efetiva inclusão.

A partir das análises estabelecidas no âmbito do grupo de pesquisa, alguns elementos vêm sendo considerados consenso quanto à sua pertinência ou não. A lixa, que incialmente, para muitos, parecia ser um elemento interessante na confecção dos livros, foi desencorajado e desmistificado a partir da consultora e de alguns testes com crianças. Sua textura não é agradável ao toque e não agrega valor à obra. Materiais de fácil 
degradação não foram usados, pois têm pouca durabilidade. Outro aspecto importante a ser ressaltado refere-se à não utilização de materiais que a criança possa levar à boca, considerando a faixa etária para a qual os livros são pensados ( 3 a 8 anos).

Alguns elementos vêm sendo muito usados e encontraram destaque: o feltro e o EVA. Esses materiais, em suas várias diagramações e texturas, mostraram-se muito ricos em possibilidades. Um dos usos prioritários se deu como textura na elaboração de bases das histórias, tal como grama, asfalto, etc. Vários tipos de cola vêm sendo testados com materiais bastante variados. Produziu-se um "livro teste", no qual se inserem materiais e colas, sendo experimentados e avaliados. A forma de colagem considerada mais apropriada, até o momento, é a com fita dupla face em suas diversas larguras.

Observamos, ainda, o fato de os livros, para as crianças que estão iniciando seu contato e experiências com tais objetos, poderem ser mais interessantes quando apresentam pistas ou padrões ao usuáriolleitor, como conter sempre uma página para a escrita e outra para as imagens.

Na maioria dos livros protótipos, a escrita em tinta e braille estava à esquerda e as imagens, à direita. Podemos notar essa tendência, também, nos livros produzidos pela Federazione Nazionale delle Istituzioni pro Ciechi de Roma. Observamos que, na organização dos livros, eleger um padrão para o uso da escrita em tinta e em braille no livro, e não em todos os livros, permite certa estabilidade e possibilidade de busca autônoma às crianças iniciantes em seus acessos aos livros infantis.

Um dos livros produzidos trazia a indicação de texto em braille e tinta na base à direita, mas, em uma das páginas, isso ocorreu na esquerda. Ao observarmos a filmagem, vemos a menina que estava lendo, ao virar a página, procurar a escrita como aparecera até então. Ao não encontrar, buscou outros espaços. Possibilitou-se observar, ainda, que livros ricos em imagens texturizadas e coloridas, com inserção ou não de outros elementos multissensoriais, foram bem aceitos e propiciaram o encontro em movimentos de leitura entre crianças que enxergam e crianças com baixa visão ou cegas. Segundo Polato, "Através dos livros ilustrados, a criança com deficiência visual tem a oportunidade de socializar, refinar a exploração tátil e conhecer o simbolismo da língua escrita" (Polato, 2010, p. 2)

Foi possível perceber a importância em apostar em processos de comunicação, envolvendo o uso de livros infantis e materiais diversos adequados/adaptados, buscando abrangência multissensorial. $\mathrm{O}$ enfoque deste projeto permitiu atividades de investigação, desenvolvimento e inovação na produção de materiais e de livros ilustrados táteis.

\section{Considerações finais}

Ao iniciar a escrita das considerações finais, sublinhamos pontos de força e de fragilidade no processo de pesquisa na direção de efetivar a produção de literatura para crianças com deficiência visual.

Ao analisarmos os protótipos produzidos durante a pesquisa, alguns elementos se destacam: a importante possibilidade que tivemos em produzir um suporte para a produção dos livros; a definição de aspectos como textura, dimensões, durabilidade que pareceram mais apropriadas ao uso pretendido. Em relação à dimensão do suporte, percebemos a possibilidade de aumentar o número de páginas, no entanto, não devendo ser muito maiores, pois dificultam às pequenas mãos dos leitores explorarem com tranquilidade. 
O livro ilustrado tátil mostrou-se uma grande oportunidade para a busca de uma interlocução e de um espaço de diálogo entre o texto e a e a acessibilidade ao mesmo. Crianças pequenas têm na imagem seu principal desafio. No livro ilustrado tátil, a imagem provoca encantamento a todas as crianças.

O projeto de pesquisa tem como proposta o estudo das possibilidades de adaptação/adequação de literatura infantil com o intuito de ampliar a inclusão por meio da acessibilidade a livros com braille e com tinta em fonte ampliada e imagem tátil. Este projeto se alinha à Política Nacional de Educação Especial na Perspectiva da Educação Inclusiva (2008), na medida em que o livro, como produção cultural, igualmente, pode ser acessado por crianças com deficiência visual.

Uma das áreas fundamentais que faz parte da pesquisa é a Tecnologia Assistiva (TA), a qual permeia a área do conhecimento de característica interdisciplinar com enfoque nos estudos sobre Comunicação Aumentativa ou Alternativa, para ampliação de habilidades de comunicação aos sujeitos com necessidades de adequações multissensoriais.

Destacamos a relevância em produzir outros processos de comunicação, envolvendo o uso de Tecnologia Assistiva, utilizada em materiais diversos e, no caso deste projeto, em livros ilustrados táteis. É importante ressaltar que não podemos considerar o processo de comunicação restrito unicamente à linguagem oral ou escrita, já que esta envolve, também, aspectos relativos à intersubjetividade e a recursos diversos que possibilitam a invenção de novas formas de comunicação.

Em 2018, desencadearam-se dois movimentos: o primeiro foi o curso de extensão oferecido a professores de escolas públicas e a alunos da graduação e pós-graduação da UFRGS na intenção de produzir livros acessíveis táteis. Na segunda etapa da ação, em trabalho multidisciplinar, desenvolveram-se livros que pudessem ser multiplicados em série.

Desenvolver livros ilustrados táteis para crianças com deficiência visual foi o mote desta pesquisa que, neste momento, já conta com uma publicação finalizada e duas outras em fase de finalização. A parte gráfica tem sido montada, pensando o contorno dos objetos, o uso de cores contrastantes, definindo formas e utilizando a configuração das figuras em módulos que, eventualmente, podem se sobrepor, transmitindo noções de distância e de proporção importantes.

$\mathrm{Na}$ escolha dos materiais, consideraram-se, ainda, características como suavidade, resistência, fácil higiene e identificação pelo tato. A utilização da máquina de corte a laser para tal produção vem garantindo maior precisão e otimização do processo. Novos formatos vêm sendo pesquisados e desenvolvidos pela equipe, como a audiodescrição enquanto recurso essencial para a orientação da exploração tátil e elemento promotor da interação do livro com o livro e entre os leitores, pois abre novas possibilidades e formas de fruição das obras.

A pesquisa, hoje, conta com algumas dezenas de protótipos desenvolvidos junto ao grupo de pesquisa. Como resultados iniciais da pesquisa, temos a publicação de uma história em versão impressa em braille e tinta em fonte ampliada, com imagens ilustradas táteis, com versão digital em audiolivro com audiodescrição. Dois outros livros estão em fase final de produção. A alegria das crianças que tiveram acesso aos livros define a direção e andamento da pesquisa. 


\section{Referências}

Brasil. (2014). Anuário Brasileiro da Educação Básica, 2014. Recuperado de http://educacaosec21.org.br/wpcontent/uploads/2013/07/anuario_educacao_2013.pdf.

Brasil. (2003). Lei $n^{o} 10.753$, de 30 de outubro de 2003. Institui a política nacional do livro. Recuperado de https://www.planalto.gov.br/ccivil_03/LEIS/2003/L10.753.htm.

Brasil. (2009). Decreto $n^{o}$ 6.949, de 25 de agosto de 2009. Recuperado de http://www.planalto.gov.br/ccivil_03/_ato2007-2010/2009/decreto/d6949.htm.

ONU. (1948). Declaração Universal dos Direitos Humanos. Recuperado de https://nacoesunidas.org/wp-content/uploads/2018/10/DUDH.pdf.

Jesus, D. M., Baptista, C. R. e Caiado, K. (Orgs.) (2013). Prática pedagógica na educação especial: multiplicidade do atendimento educacional especializado. Araraquara: Junqueira \& Marin.

Nuernberg, A. H. (2010). Ilustrações táteis bidimensionais em livros infantis: considerações acerca de sua construção no contexto da educação de crianças com deficiência visual. Revista Educação Especial, Santa Maria, jun. Recuperado de https://periodicos.ufsm.br/educacaoespecial/article/view/1438.

Passerino, L.M. (2015). A tecnologia assistiva na política pública brasileira e a formação de professores: que relação é essa? Em Baptista, C.R. (Org.) Escolarização $e$ Deficiência. Recuperado de https://www.lume.ufrgs.br/ bitstream/handle/10183/116615/000967541.pdf?sequence $=1$.

Passerino, L.M. e Montardo, S. (2007). Inclusão social via acessibilidade digital: proposta de inclusão digital para pessoas com necessidades especiais. Revista da associação nacional dos programas de pós-graduação em comunicação. Abril, 2007. Recuperado de http://www.compos.org.br/seer/index.php/e-compos/article/ view/144/145.

Polato, E. (2013). La lettura di un TIB (Tactile Illustrated Book) come contesto per l'espressione di domande da parte dei bambini con deficit visivo. Una ricerca esplorativa. Università degli Studi di Padova Dipartimento di Filosofia, Sociologia, Pedagogia e Psicologia Applicata. Scuola di Dottorato di Ricerca. Scienze Pedagogiche, dell'Educazione e della Formazione, CICLO XXIII.

Polato, E. (2010). Per immaginare, la mente ha bisogno di immagini. L'importanza dei libri illustrati tattilmente come mediatori per l'alfabetizzazione e la relazione nei bambini inetà prescolare - Contributo in occasione della manifestazione "Libri che prendono forma", MiBAC - FNIPC. 
Piccardi, F. (2011). I libri tattili illustrati nel processo di educazione all'immagine. Del bambino con deficit visivo. Recuperado de https://www.bibliotecaciechi.it/sites/default/files/imported/tiflologia/tiflologia/2 01201/Piccardi.doc.

Linden, S. V. D. (2011). Para ler o livro ilustrado. São Paulo: Cosac Naify.

Lins, G. (2003). Livro Infantil?: projeto gráfico, metodologia, subjetividade. São Paulo: Edições Rosari.

Lourenço, D. A. (2011). Tipografia para livro de literatura infantil: desenvolvimento de um guia com recomendações tipográficas para designers. Dissertação de mestrado. Programa de Pós-Graduação em Design, Universidade Federal do Paraná.

McCannon, D., Thornton, S. e Williams, Y. (2008). The Bloomsbury guide to creating illustrated children's books. London: A\&C Black Publishers.

\footnotetext{
${ }^{i}$ Multi (https://www.ufrgs.br/multi/): Projeto que tem como objetivo desenvolver literatura para todos por meio de livros acessíveis em multiformato. A equipe é composta por diferentes unidades acadêmicas da Universidade Federal do Rio Grande do Sul (UFRGS) e tem parceria com profissionais das áreas da educação e de acessibilidade comunicacional, contando, também, com a participação de bolsistas de iniciação científica e de extensão.

ii O programa do Governo Federal, promovido pelo MEC - "Pacto pela Alfabetização na Idade Certa: o Brasil do futuro com o começo que ele merece", tem suas ações iniciadas em 2012 e reproduzidas em todo o País.

iii Projeto Universal - aprovado 2016 com início 2017: literatura infantil para diversidade: livros acessíveis.

iv $\mathrm{O}$ suporte tem como inspiração os produzidos pela "Federazione Nazionale delle Istituzioni pro Ciechi" in http://www.prociechi.it/

v O INCLUIR é o Núcleo de Inclusão e Acessibilidade, setor responsável por desenvolver estratégias de inclusão, acessibilidade e permanência de pessoas com deficiência, com e para a comunidade universitária, no âmbito do ensino, pesquisa, extensão e gestão administrativa.
}

Data de recepção: 07/10/2019

Data de revisão: 08/07/2020

Data do aceite: 14/07/2020 